\title{
Rule-BASEd ForWARD CHAINING TECHNIQUE FOR DETECTING AND CONTROLLING FRAUd IN Project Monitoring System
}

\author{
Abas $\mathrm{A}^{1}$, Oshoiribhor E. $\mathrm{O}^{2}$ and John-Otumu M. $\mathrm{A}^{3}$ \\ ${ }^{1}$ Department of Computer Science, Auchi Polytechnic, Auchi, Nigeria \\ ${ }^{2,3}$ Department of Computer Science, Ambrose Alli University, Ekpoma, Nigeria
}

\begin{abstract}
The increasing nature of construction or building project and the continuous nature of fraudulent activities being executed by the contractors on site has led project engineers / managers the quest for software solutions for monitoring and managing project activities from start to finish. The software solutions for managing construction projects like the Microsoft projects, Project commander, Procore, Co-Construct, etc which can only solve problems of project planning and activities scheduling but cannot handle preplanning processes like workflow activities between the stakeholders and also cannot handle fraud detection or control in on-going projects. This research work proposed a model and developed a web based software solution based on the proposed architectural model to fill in the gap. The Rule-based forward chaining techniques was used to realize the fraud detection and control objective. Use-case diagram was used to model the application behavior. HTML, JavaScript, Hypertext Preprocessor (PHP), jQuery and MySQL implementation tools were used to develop the software prototype. The proposed system was tested; results revealed that the system is able to achieve its objectives effectively.
\end{abstract}

\section{KEYWORDS}

Fraud Control, Automated workflow, Project monitoring, Rule-based system

\section{INTRODUCTION}

Project monitoring and fraud control is one of the most important tasks of construction project management. Every team member needs to know in a timely and accurate manner, how the project is progressing, where they are currently in comparison to the initially set plans, whether deadlines are met, budgets are safely measured, fraud are controlled and followed. Nigeria and some other countries in Africa know what fraud has done to humanity. Many men and women are known for fraud in all areas of activities [1]. Intentional deception by concealing or misrepresenting information that harms the financial interest of another person(s) and benefits the financial interests of the perpetrator is fraud. A successful project completion requires the concerted effort of the project team to carry out the various project activities. It is the project manager who is the center of the project network that is responsible for orchestrating the whole construction process. The project manager has to maintain the project network and monitor against slippages in cost, time and quality during the entire project duration. In achieving this; the project manager relies heavily on a reliable monitoring system that can provide timely signaling of project problems, whether they are real or potential [2].

Nevertheless, for many organizations not only do they not have a documented process for managing the project life cycle but they also lack having the internal control and audit that will

DOI: $10.5121 /$ ijsea.2017.8503 
prevent those involved in delivering the project from committing project fraud. Control activities are the policies and procedures that help ensure management directives are carried out. It helps ensure that necessary actions are taken to address risks in the achievement of the entity's objectives. Control activities occur throughout the organization, at all levels and in all functions. They include a range of activities as diverse as approvals, authorizations, verifications, reconciliations, reviews of operating performance, security of assets and segregation of duties. Project fraud is the misrepresentation of a project's mission or progress to secure project financing, reporting wrong project progress to hide project delays and/or budget overrun, wrong forecasting for expected project cost at completion to avoid reporting lower project profitability, overestimating the value of anticipated changes to the project scope to increase the project value, misuse of project resources, and/or improper dealings with project vendors for personal enrichment, substituting specified equipment and materials with lower quality alternatives, among many others [1].

Fraud is very much a part of most businesses and construction projects are not exempted. Actually, there are more chances of fraud in project construction than other type of businesses, especially when it comes to engineering and construction projects. Project fraud often originates because employees don't want to report bad news or information that can harm them politically or career wise. Poor planning and supervision often leads to project rework, placing the project further behind. The most common types of project fraud includes over-reported and unsubstantiated business case or feasibility studies, unsubstantiated project decisions, underreported initial estimates of project lifecycle costs, under-reported initial estimates of project maintenance costs, setting unrealistic project completion dates, unbalancing the project cost estimate, under-reported costs, over reported schedule progress, over-reported quality progress, project asset misuse, vendor conflict of interest and kickbacks, vendor "overselling" of their capabilities and inappropriate vendor charges.

The effectiveness of many construction organizations to monitor the materials used in their projects is constrained by the inability to stay with project during execution. Most projects are executed with sub-standard materials; projects are delayed and sometime abandoned due to poor monitoring method. The few project monitoring applications available like Primavera Project Planner (P3), Microsoft Projects, Project commander, and so on are rather passive application than active i.e. the applications are not reactive to input data; they are used in scheduling project activities in order to monitor the project critical path from start to finish and not truly monitoring the project for fraudulent activities that can occur from start to finish which is the gap this research work intends to fill. The objectives of this research work are as follows:

i. To develop an automated workflow mechanism for initiating and routing the bill of quantities amongst the project key players for certification and final approval.

ii. To develop a reactive mechanism for monitoring project activities in order to detect and control fraudulent activities by the project contractor using a rule-based forward chaining technique for classification. 
International Journal of Software Engineering \& Applications (IJSEA), Vol.8, No.5, September 2017

\section{LITERATURE REVIEW}

Every year, many projects are awarded by the government to make life meaningful to its citizens. Most projects are abandoned or not completed due to fraudulent act from the contractors in collaborations with the manager in charge of project monitoring. Project control is often a complex task undertaken by project managers in practice. During the last few decades, numerous planning and control techniques, such as Gantt Bar Chart, Program Evaluation and Review Technique (PERT), Earned Value Analysis, Critical Path Method (CPM), have been developed. A variety of software packages have also become available to support the application of these project control methods, for example Microsoft Project, Asta Power Project, Primavera Project Planner (P3), etc.

[3] reported that most of the important variables causing construction delays and cost overruns in Nigeria are due to poor contract management, financing and payment of completed works, changes in site conditions, shortage of materials, imported materials and plant items, design changes, subcontractors and nominated suppliers. While the top variables causing only cost overruns were revealed as price fluctuation, inaccurate estimates, delays, and additional works. One area of research effort is the development of Information Technology (IT) based project control systems is based on established control techniques. For example, [4] developed a new system for cost control based on the earned value concept, which was specifically aimed at small and medium sized companies. Similarly, [5] designed a comprehensive model for planning and controlling contractor cash-flow by adapting the earned value management techniques. [6] Pointed out that standard control method, such as the earned value method applies a deterministic approach which may be insufficient as they ignore the variable nature of projects. A probabilistic project control model that uses performance control limit curves and stochastic S-curves was developed; noting that it will be more effective for projects with uncertain performance behavior. Other researchers went beyond simple implementation of project control techniques by proposing new project control methods. [7] Argued of the need for an integrated model that facilitates efficient planning of repetitive construction processes. Hence, a model was developed by integrating the schedule and cost information with resource information inputted to the project. The PCIM model proposes that irrespective of the results of the analysis, systems and processes should be put in place to feedback the findings to the site and project management teams. In practice, transfer of project control information is often only one way; from the site to the project office. The project office rarely provides feedback on their findings to the site team with the exception of when the findings are negative. The PCIM model suggests the use of a feedback report from the project control team sent at set periods to the site team. This will go a long way in motivating the site team that the monitoring and reporting they carry out and transmit to the project office is not useless information but is actually being used.

Finally, having a dedicated Feedback procedure ensures that information is transmitted quickly and efficiently and is not left on the desk until it becomes obsolete and useless [8]. 
International Journal of Software Engineering \& Applications (IJSEA), Vol.8, No.5, September 2017

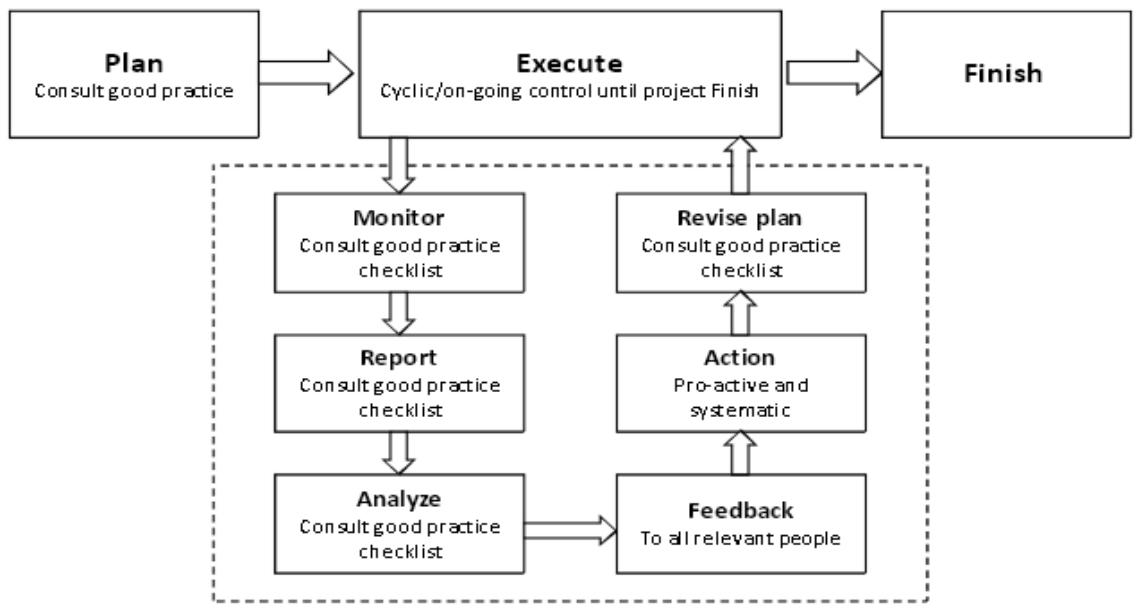

Figure 1: A Project Control and Inhibiting-Factors Management Model [8]

\section{Methodology}

This research work focuses on the shorting comings of the research work cited by [8]. We made a modification to the PCIM model in Figure 1 by adding an automated workflow system and a fraud control mechanism in order to route messages between users and to detect and control fraud in construction project and also to report event occurrence in a near real-time process.

\subsection{Proposed System Architecture}

System architecture is a conceptual model that defines the structure, behavior, and more views of a system. It is a formal description and representation of a system, organized in a way that supports reasoning about the structures and behaviors of the system.

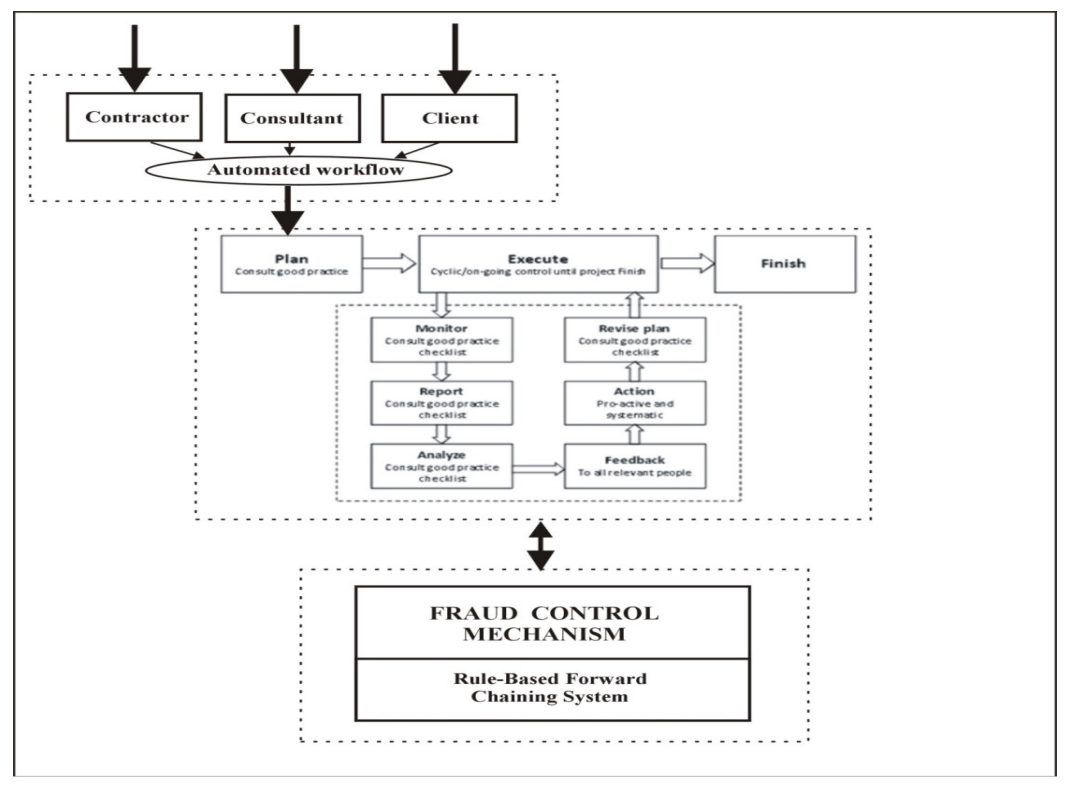

Figure 2: Proposed system architecture 
International Journal of Software Engineering \& Applications (IJSEA), Vol.8, No.5, September 2017

Figure 2: shows the proposed system architecture of this research work; the architecture is sub divided into three major parts:

(a) The Automated workflow mechanism

(b) The PCIM model

a. Top section [Planning, Execute and Finish]

ii. The Middle section [Monitor, Report, Analyze, Feedback, Action, and Revise Plan]

iii. Bottom section

(c) The Fraud control mechanism

The process flow starts from the automated workflow mechanism that allows the client user to initiate a project bidding process by advertisement, thereafter contractors sends in their various bids for selection; a particular contractor is selected for the project after several deliberations before the project starts properly. The mechanism also allows the moving of information between the client, consultant and the contractor and vice versa as the case may be for proper information dissemination and monitoring.

The next phase is the planning stage, in which the entire project is broken into activities, scopes and levels with a Bill of Quantity (BoQ) to follow per scope and level (See figures 5 and 6). In this phase the contractor initiates the BoQ required to execute the project and route it to the client, the client acknowledges receipt and also route it to the project consultant in-charge for validation and verification before final approval is given for project commencement.

The next phase is the execution stage; in which both the contractor and project consultant representatives review the entire project to be executed together level by level, and also set different policies for different levels of work to be carried out. This involves assigning a given number of days per job level, setting up of a threshold value as a benchmark for monitoring and control of fraudulent activities, etc. (See figure 7); thereafter, the consultant's and contractor's representatives gather data on a daily basis for the on-going project on site from start to finish. They both have separate profile on the web based project monitoring system in which they could $\log$ into in order to feed in the data gathered as per usage per day via the daily input interface at the end of each day's job and also from different location.

Note: The fraud control mechanism checks the daily input entered by the contractor and the consultant, sums the entries daily until it get to the policy set up per level for a given number of days; it then automatically stops the entry for that particular level. It compares the contractor and consultant daily entries for any noticeable differences; it compares the sum total per level for both the contractor and consultant, and finally compares the sum total per level for both the contractor and consultant against the policy or threshold value set per level before execution for any slight differences. Ideally, the sum total per level ought not to exceed the threshold value per that same level for both entries i.e. contractor's and consultant's entries. So, any changes noticed by the fraud detection mechanism will automatically trigger the notification system to signal the administrator of an attempted fraud! (See figures 9 and 10)

\subsection{RULE-BASED SYSTEM}

A rule-based system (RBS) provides an automatic problem solving tools for capturing the human expertise and decision making. RBS is a means for codifying the problem solving of human 
International Journal of Software Engineering \& Applications (IJSEA), Vol.8, No.5, September 2017

experts. Experts in this sense, typically expresses most of their problem solving techniques in terms of antecedent-consequent rules. Basically the RBS support two types of techniques: The forward and the backward chaining techniques. The Forward chaining mode of operation means that a rule is triggered when changes in the working memory produce a situation that matches all of its antecedents. Forward chaining is the process of inferring THEN-patterns from IF-patterns; that is consequents from antecedents. When an antecedent matches an assertion the antecedent is satisfied. When all antecedents of a rule are satisfied the rule is triggered. While in the backward chaining mode of operation, the system begins with a goal and successively examines any rules with matching consequents. The candidate rules are considered one at a time. The conditions unmet are re-introduced as new goals. The control process will then shift attention recursively towards the new goal. The whole process terminates when the top goal is finally satisfied.

In this research paper, we used the forward chaining technique in building the fraud detection mechanism. Figure 3 shows the rule based forward chaining algorithm for our proposed fraud detection mechanism in project monitoring system.

\section{Rule-based forward chaining algorithm for fraud detection in project monitoring}

1: // Set Policy P for different layers (L, M, S) // Threshold or Confidence Value

2: Input $\mathrm{P}(\mathrm{L})$

3: Inputs: Contractor <- lower structure level (L), middle structure level $(\mathrm{M})$, super structure level (S)

4: Inputs: Consultant <- lower structure level (L), middle structure level (M), super structure level (S)

5: Outputs: Classifier $->$ Normal, Fraud Attempt

6: Compute Contractor Layers (CL1) $=\mathrm{L}+\mathrm{M}+\mathrm{S}$

7: Compute Consultant Layers (CL2) $=\mathrm{L}+\mathrm{M}+\mathrm{S}$

8: Set Rules for Classification

9: Rule (R1):

10: If CL1(L) $\neq$ CL2(L) .OR. CL1(M) $\neq$ CL2(M) .OR. CL1(S) $\neq$ CL2(S)

11: $\quad$ Then Display "Alert! Variance in Layers" $\rightarrow$ D1

12: Rule (R2):

13: If Contractor $($ Total $($ Layers $\rightarrow(\mathrm{L}+\mathrm{M}+\mathrm{S}))<>$ Policy $(\mathrm{P})$.AND. Consultant $($ Total $($ Layers $\rightarrow(\mathrm{L}+\mathrm{M}+\mathrm{S}))$

$<>$

14: $\quad$ Policy (P) Then Display "Alert! Fraud Attempt" $\rightarrow$ D2

15: Rule (R3):

16: If Contractor $($ Total $($ Layers $\rightarrow(\mathrm{L}+\mathrm{M}+\mathrm{S}))=$ Policy $(\mathrm{P})$.AND. Consultant $($ Total $($ Layers $\rightarrow(\mathrm{L}+\mathrm{M}+\mathrm{S}))=$ Policy (P)

17: Then Display "Normal" $\rightarrow$ D3

18: $\quad$ Endif

19: $\quad$ Endif

20: Endif

21: Output D1, D2, D3

22: Stop

Figure 3: Rule-based forward chaining algorithm

\subsection{SYSTEM MODELING USING UML DiAGRAM}

Unified Modeling Language (UML) is a standardized general-purpose modeling language in the field of object-oriented software engineering. It includes a set of graphic notation techniques to create visual models of objects-oriented software intensive systems. We used the use-case, 
International Journal of Software Engineering \& Applications (IJSEA), Vol.8, No.5, September 2017

diagram to model our application behavior because it provides a wide array of diagrams for analysis and design modeling at both the system and the software level.

\subsection{USE-CASE}

A use case diagram is a representation of a user's interaction with the system.

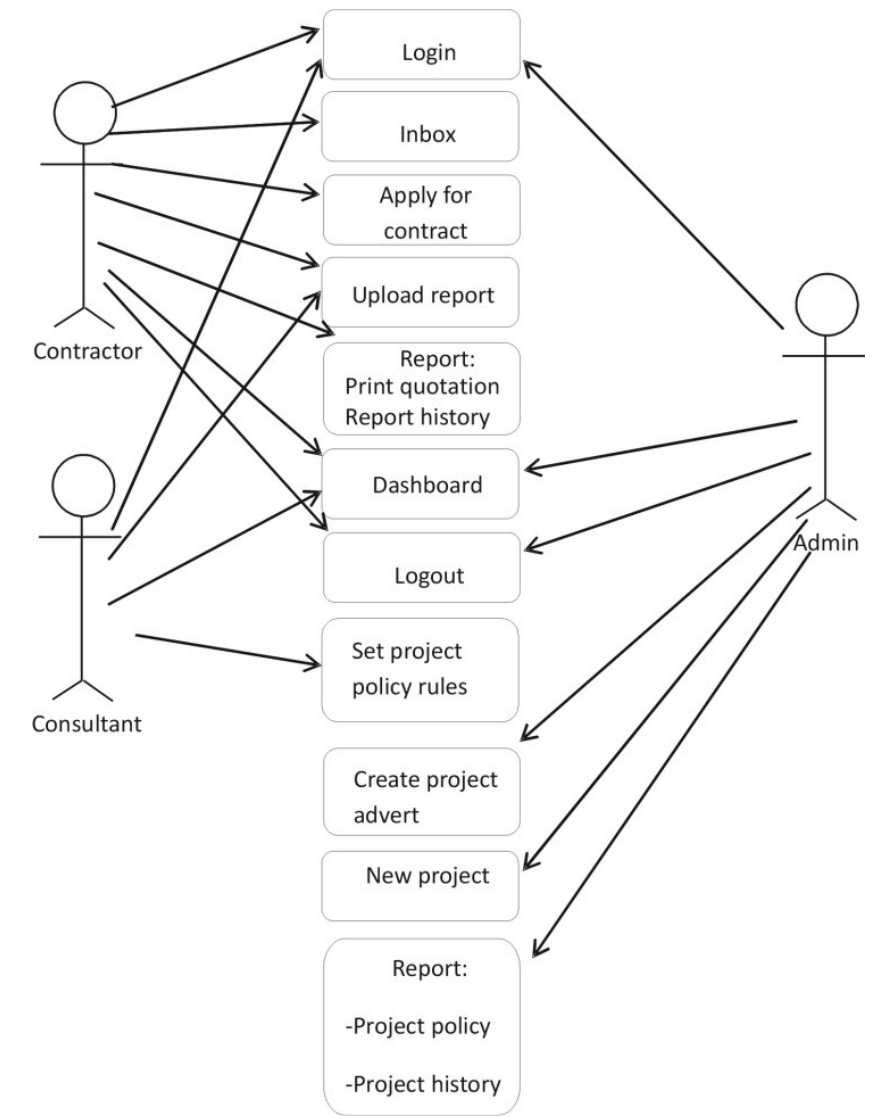

Figure 4: Users interaction with the developed system features

Figure 4 portrays the interaction between the contractor, consultant and admin users with the system and its features at their various levels.

\section{RESULTS}

The results of the proposed system are itemized below

a. The proposed system has simple user interfaces with well-structured workflow process that aids easy interaction or communication between all the system users.

b. The proposed system is able to capture and route data between the system users using the automated workflow mechanism developed. 
International Journal of Software Engineering \& Applications (IJSEA), Vol.8, No.5, September 2017

c. The proposed system is able to detect and control fraudulent attempts in the project system from both the contractors and consultants entries setting up policies for the project and using rule-based forward chaining technique for classification.

d. The proposed system is able to conveniently predict areas in the construction project where there are likely variances with the set policies for easy decision making on project completion.

e. Finally, the proposed is able to display near real-time report.
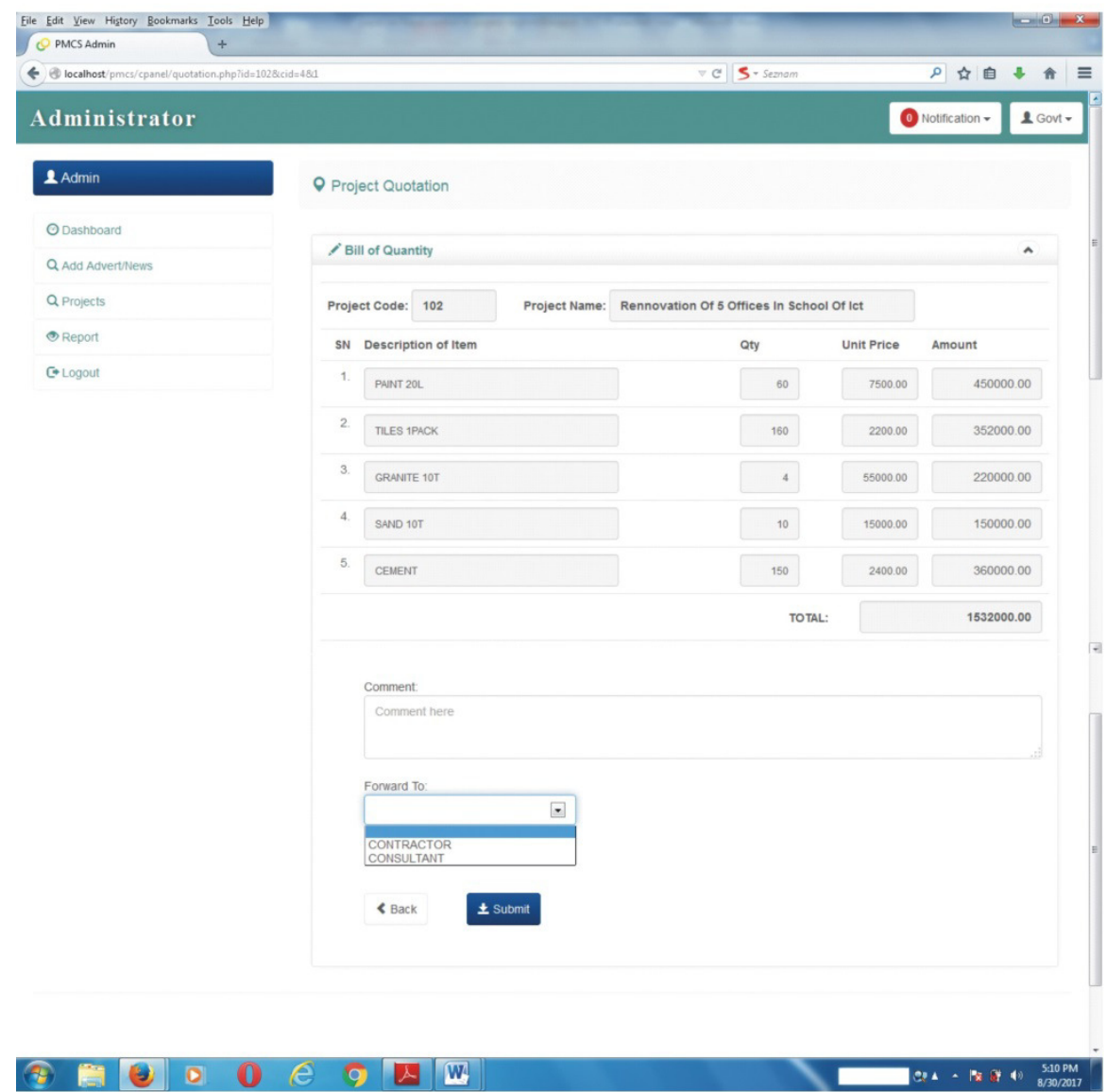

Figure 5: Project Application Form for Bill of Quantity 
International Journal of Software Engineering \& Applications (IJSEA), Vol.8, No.5, September 2017
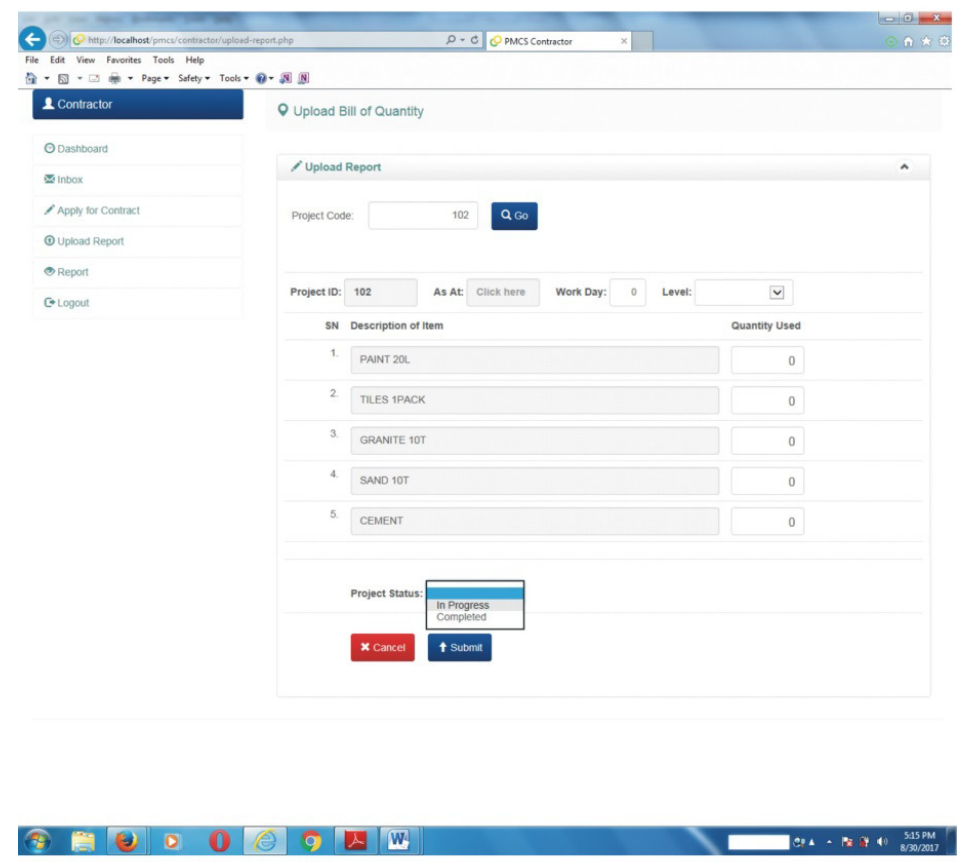

Figure 6: Report Upload Form

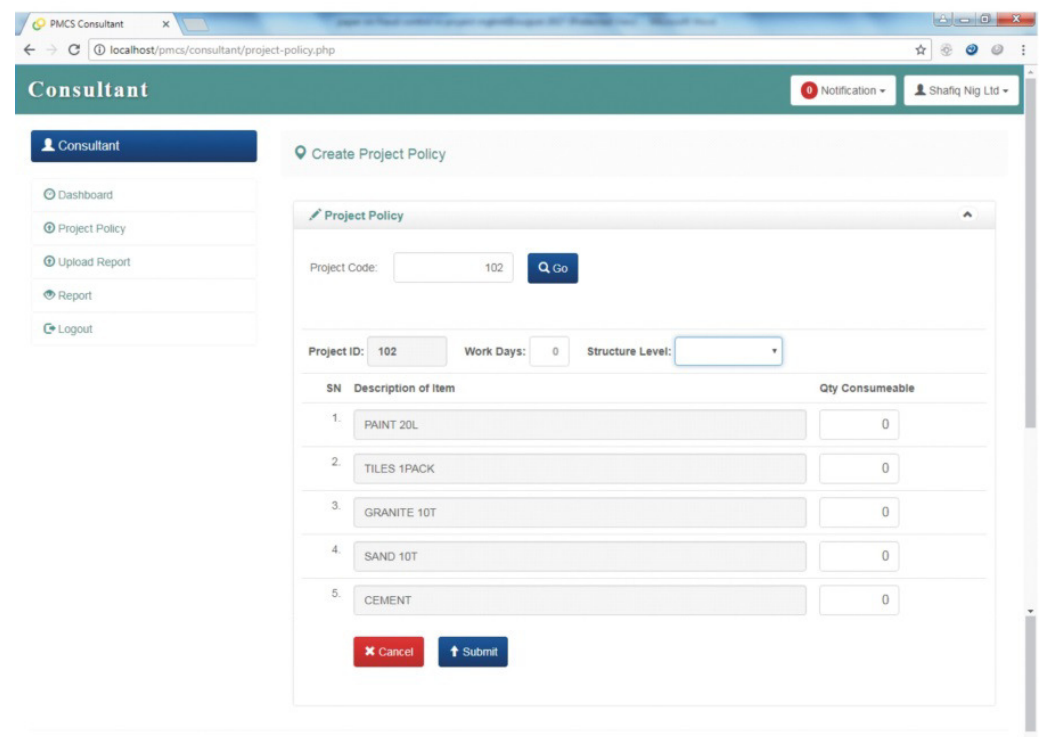

(3)

Figure 7: Project Policy Form 
International Journal of Software Engineering \& Applications (IJSEA), Vol.8, No.5, September 2017

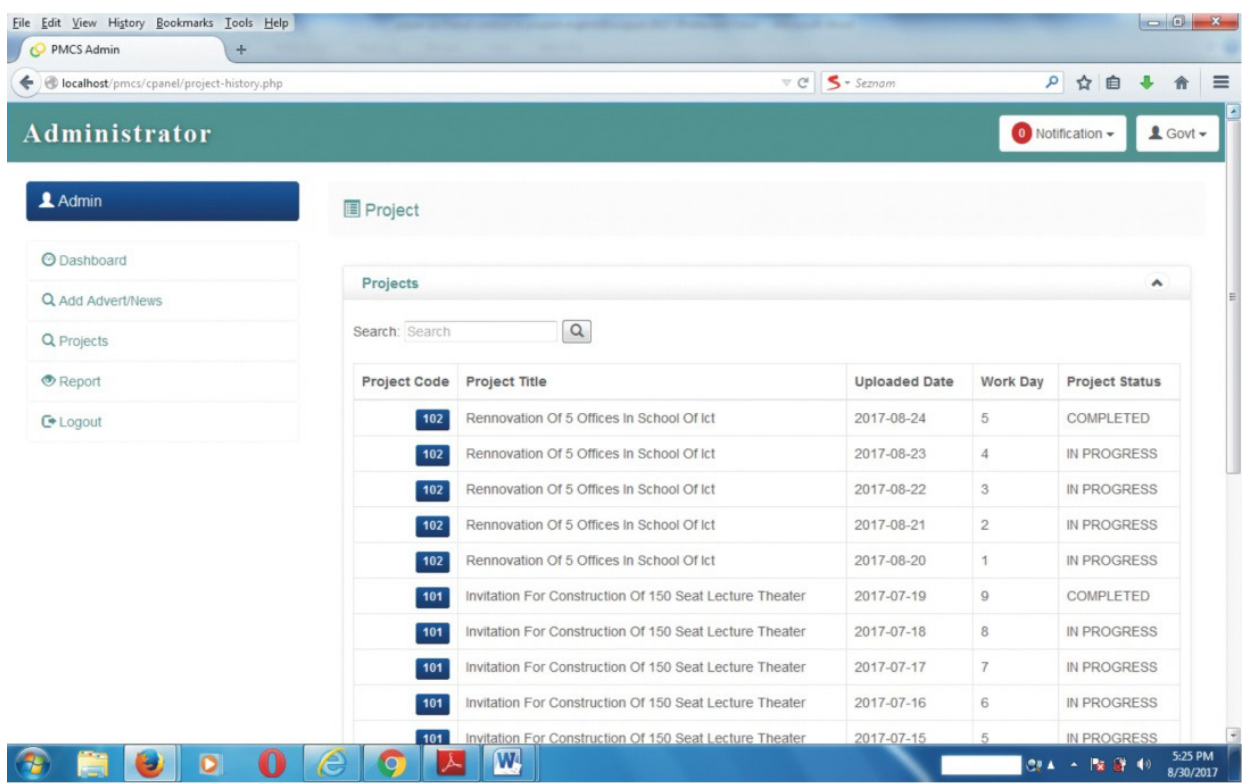

Figure 8: Project Report History Interface

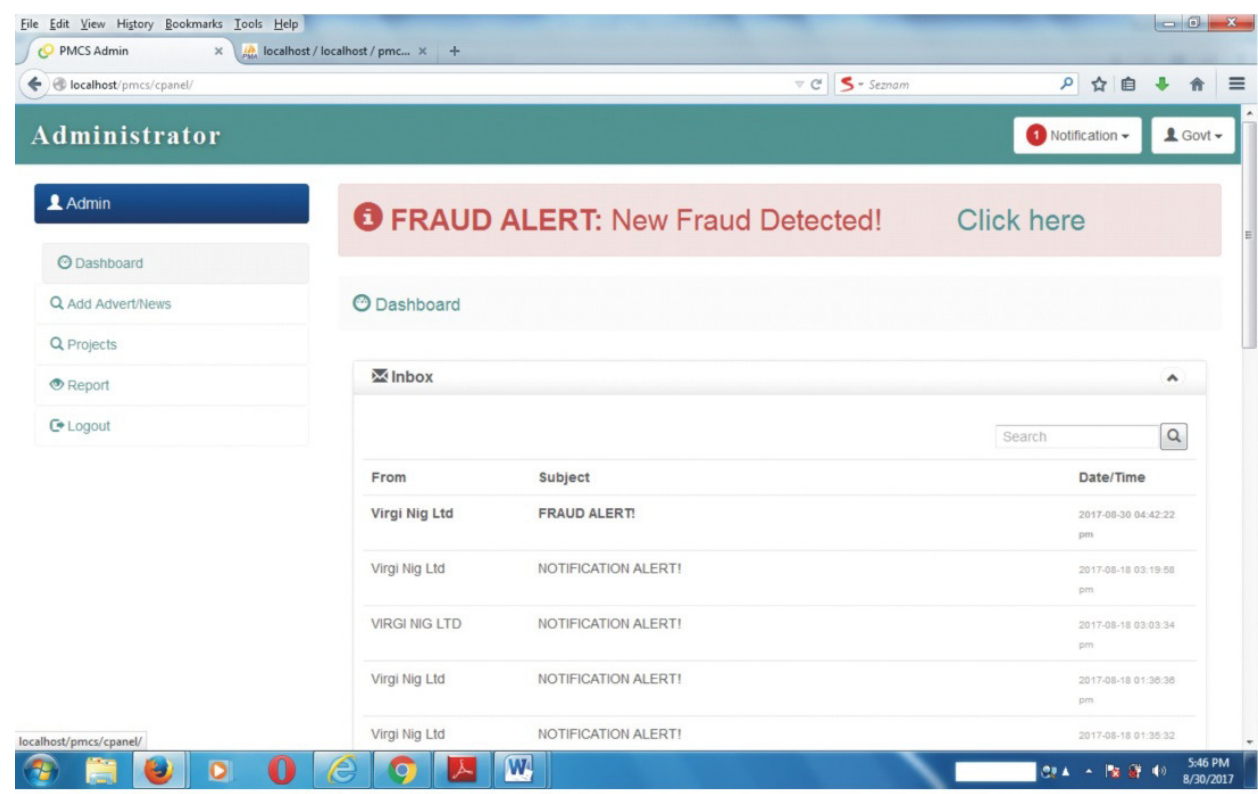

Figure 9: Fraud Alert Board Interface 
International Journal of Software Engineering \& Applications (IJSEA), Vol.8, No.5, September 2017

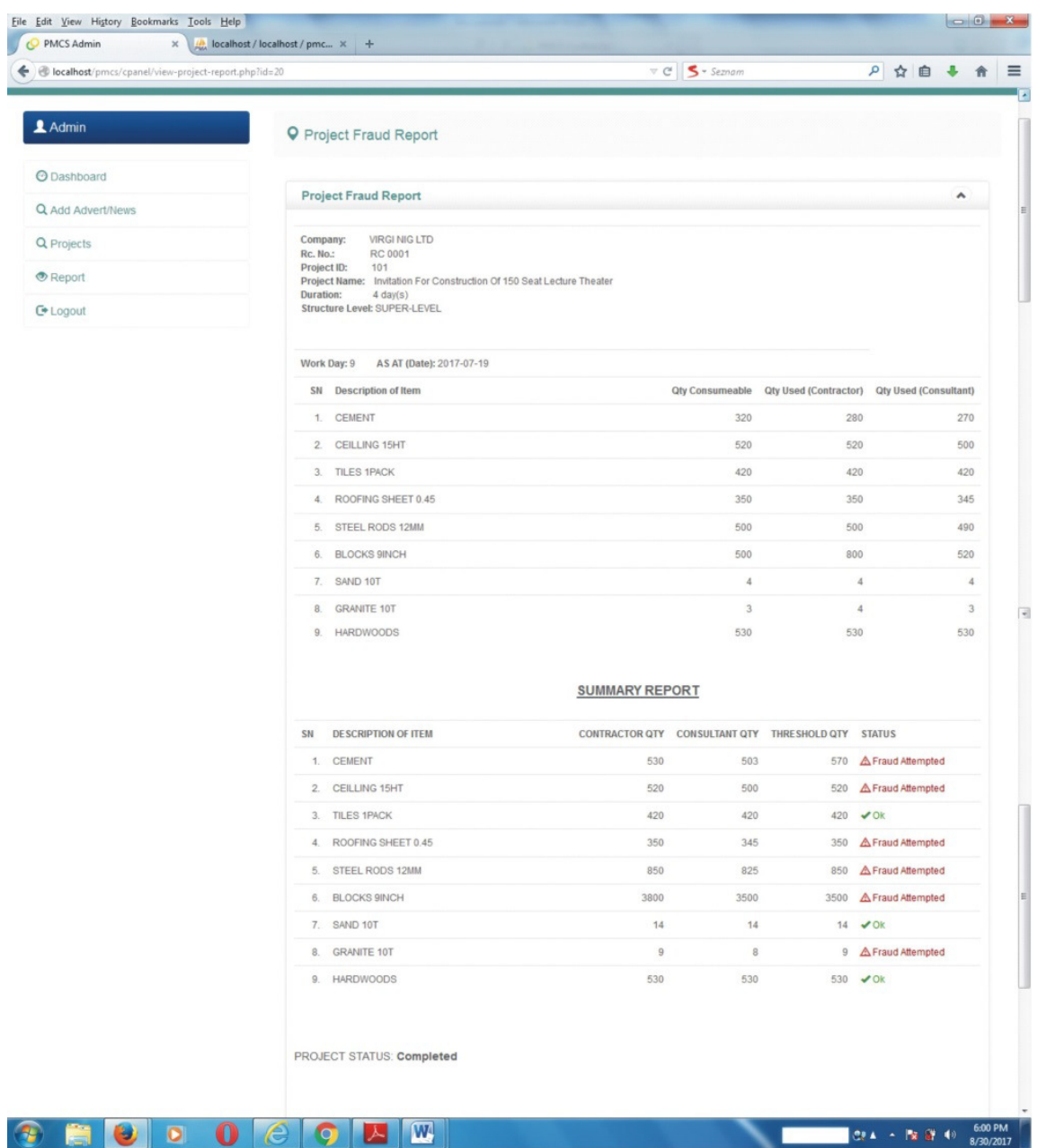

Figure 10: Report interface for attempted fraud

\section{DisCUSSION}

Figures 5, 6, 7, 8, 9 and 10 shows screenshots of different interfaces captured from the proposed software solution for fraud control in project monitoring system developed as a result of the research work.

\section{CONCLUSION}

The problem of fraud detection and control in construction projects management is a very challenging one. We achieved our desired aim and objectives by modifying the PCIM model to have automated workflow system for static routing of information between users and making the model intelligent to detect and control fraud in project monitoring system using rule-based forward chaining algorithm. The system results evaluated shows that the proposed system was rated higher in terms of specific system functionalities as compared to the other four off-theshelve software applications for project management. 
International Journal of Software Engineering \& Applications (IJSEA), Vol.8, No.5, September 2017

\section{FUTURE WORK}

In this research work, we considered the following functional components in building the project monitoring software prototype; automated workflow mechanism for routing information between system users for project initiation and planning, detection mechanism for fraudulent activities using rule-based technique, report via screen notification system.

However, future work should consider legacy design in terms project planning and activities scheduling by inculcating PERT or CPM. Also, in the areas of fraud detection and control, rulebased technique has its own shortfall as soon as the logic increases; therefore, advanced data mining techniques should be investigated for building better intelligence in fraud detection and control mechanisms. Finally, for reporting at a near real-time; SMS and email should also be considered for integration.

\section{REFERENCES}

[1] Bassam S. (2013). Can a Professional project management stop project Fraud? At http://www.globalknowledge.com.sa/about-us/Knowledge_Center/Article/Professional-ProjectManagement/ accessed Dec 2013

[2] Zubair A. M., Muhd Z. A., and Musharirry M. (2006). A Systematic Approach for Monitoring and Evaluating the Construction Project Progress; Construction Technology and Management Centre, Journal -the Institute of Engineers, Malaysia

[3] Mansfield, N., Ugwu, O., and Doran, T. (1994). Causes of delay and cost overruns in Nigerian construction projects. International Journal of Project Management, 12 (4), 254-260.

[4] Benjaoran, V. (2009). "A cost control system development: A collaborative approach for small and medium-sized contractors.” International Journal of Project Management, 27 (3), 270 - 277.

[5] Gorog, M. (2009). "A comprehensive model for planning and controlling contractor cash-flow." International Journal of Project Management, 27 (5), 481 - 492.

[6] Barraza, G., and Bueno, R. (2007). "Probab ilistic control of project performance using control limit curves" Journal of Construction Engineering and Management, 133 (12), 957 - 965.

[7] Cho, K., Hong, T., and Hyun, C. (2010). "Integrated schedule and cost model for repetitive construction process.” Journal of Management in Engineering, 26 (2), 78 - 88.

[8] Olawale, Y. and Sun, M. (2012) PCIM: A project control and inhibiting-factors management model. ASCE Journal of Management in Engineering, 15-25 